\title{
Isolation, Identification and Antibiogram of Coagulase Negative Staphylococcus (CoNS) Isolated from Various Clinical Samples at a Tertiary Care Teaching Hospital, Jaipur, India
}

\author{
Shiv Kumar', Jitendra ${ }^{3 *}$, Anup Das ${ }^{2}$, Pratibha Mane ${ }^{4}$, \\ Jyoti Sangwan $^{4}$ and Saroj Kumari ${ }^{5}$
}

${ }^{1}$ Department of Microbiology, RNT Govt. Medical College, Udaipur, Rajasthan, India

${ }^{2}$ Department of Microbiology, NIMS Medical College, Jaipur, Rajasthan, India

${ }^{3}$ Department of Microbiology, ${ }^{4}$ Department of Microbiology,

${ }^{5}$ Department of Paediatrics, SHKM Govt. Medical College, Nalhar (Nuh), Haryana, India

\author{
*Corresponding author
}

\section{Keywords \\ Coagulase Negative Staphylococcus (CoNS), MRCoNS, MSCoNS, Typical opportunist, Nosocomial infection, Deep seated prosthetic implant infection, Antimicrobial susceptibility, Multiple drug resistance}

Article Info

Accepted:

26 December 2017 Available Online: 10 January 2018

\section{A B S T R A C T}

Coagulase-Negative Staphylococcus (CoNS) comprise an ever-expanding group of bacteria whose medical importance has emerged in the past decades. They have become one of the most frequent nosocomial pathogens isolated from blood cultures, often in association with intravascular devices and as a cause of deep-seated prosthetic implant infections (Parameswaran et al., 2011). These organisms isolated from clinical specimens with increasing frequency. So this study planned to isolate and antibiogram of Coagulase Negative Staphylococcus (CoNS) bacteria in various clinical specimens at tertiary care teaching hospital at Jaipur. The present study was carried out on total 60 Coagulase Negative Staphylococcus (CoNS) were isolated from 400 different clinical samples like Urine, Blood, Pus, Sputum, High Vaginal Swab, Semen, Nasal Swab and ET Secretion etc. from all age's group. Conventional bacteriological methods were used for identification Coagulase Negative Staphylococcus (CoNS) and susceptibility testing was performed with the help of the Modified Kirby-Bauer disc diffusion method as per CLSI guidelines 2014. This study comprises of 60 isolates of Coagulase Negative Staphylococcus (CoNS) from total of 400 clinical specimens collected from in patients admitted to various departments during a period of 6 months. Staphylococcus epidermidis was the most common isolate (38.33\%) while Staphylococcus saprophyticus (35\%) was the second most common isolated followed by Staphylococcus haemolyticus (15\%), Staphylococcus lugdanensis (5\%), Staphylococcus schleiferi and Staphylococcus xylosis have same account (3.33\%). Among all clinical samples Urine yield maximum isolates of CoNS i.e. $26(43.33 \%)$ followed by Blood 10 (16.67\%), Pus 9 (15\%), Sputum 6 (10\%), High Vaginal Swab $5(8.33 \%)$ etc. Most sensitive drug against CoNS were Vancomycin (100\%) followed by Linezolid (86.67\%), Amikacin (71.67\%). The most common species identified was Staphylococcus epidermidis. Resistance to Penicillin and Amoxyclav was high and none of the isolates showed resistance to Vancomycin. Early detection of MRCoNS and reduction in indiscriminate use of antibiotics like Vancomycin are the only suitable approaches to reduce the emergence of these drug resistant strains. 


\section{Introduction}

Staphylococci are wide spread in nature although they are mainly found living on the skin, skin glands and mucous membrane of mammals. They may be found in the mouth, blood, mammary glands, intestinal, genitourinary and upper respiratory tracts of the hosts. Staphylococcus generally have a benign or symbiotic relationship with their host; however they may develop the lifestyle of a pathogen if they gain entry into the host tissue through trauma of the cutaneous barrier, inoculation by needles or direct implantation of medical devices. Infected tissues of host support large populations of staphylococci and in some situations they persist for long periods. (Cunha et al., 2006)

Coagulase-negative staphylococci (CoNS) are divided into more than 40 species (David et al., 2012) and more than a dozen subspecies, of which approximately half have been associated with human infections. (Valle et al., 1999)

Today, Coagulase-negative staphylococci (CoNS), as typical opportunists, represent one of the major nosocomial pathogens, having a substantial impact on human life and health and accounting for $27 \%$ to $32 \%$ and $50 \%$ of such infections among adult and paediatric patients, respectively. (Bearson et al., 2004)

The Staphylococcus epidermidis is account of $75 \%$ of all clinical isolates of Coagulasenegative staphylococci and coming out as multiple drug resistance determinant make the medical management of patient more difficult. (Goyal et al., 2006)

The increasing importance of Coagulasenegative staphylococci (CoNS) also may be due in part to the growing appreciation of this group of organisms as opportunistic pathogens and to the increase in the use of transient or permanent medical devices, such as intravascular catheters and prosthetic devices, in seriously ill and immunocompromised patients (i.e., intensive care patients, premature newborns, and cancer and transplant patients). Coagulase-negative staphylococci infections often can be lifethreatening in these patients.

One of the major problems facing the laboratory is distinguishing clinically significant, pathogenic strains of Coagulasenegative staphylococci (CoNS) from contaminant strains. The vast majority of infections or diseases assumed to be caused by Coagulase-negative staphylococci (CoNS) are a significant consequence of hospitalization. (Wesley et al., 1994)

Colonization of different parts of the skin and mucous membranes of the host is the key source of endogenous infections by Coagulase-negative staphylococci. However, they are transmitted mainly by medical and/or nursing procedures.

In contrast to the situation in the 1970s, major shifts have occurred in the decade of the 1980s and in the early 1990s in the etiology of nosocomial infection. Most noticeably, the shifts have been toward the more antibiotic resistant pathogens, of which the Coagulasenegative staphylococci are a major group. Current antibiotic-prescribing practices, including preoperative antibiotic prophylaxis, have led to the selection of antibiotic-resistant organisms.

The resistance to antimicrobial agents among Staphylococci is an increasing problem. In India, methicillin resistance in Coagulasenegative staphylococci (CoNS) varies from $22.5 \%$ to $64.8 \%$ and other antibiotics show more resistance methicillin resistance in Coagulase-negative staphylococci (CoNS) (Chaudhury et al., 2007; Dar et al., 2006). 
Resistance to penicillin is either due to the presence of an altered penicillin binding protein, $\mathrm{PBP} 2 \mathrm{a}$, which has a lower affinity to penicillin, encoded by mecA gene carried on the SCC mec element or due to the production of $\beta$-lactamases (Deurenberg et al., 2007; De Lencastre et al., 1991). Conventional phenotypic methods of detection include disc diffusion / MIC testing with oxacillin and cefoxitin or oxacillin agar screening (Anand $e t$ al., 2009)

Because of continuous increase in antibiotic resistance, led to renewed interest in the usage of Macrolide-Lincosamide-Streptogramin B (MLS) antibiotics to treat Staphylococcus infections. The macrolide-lincosamidestreptogramin B (MLS) group of antibiotics which are structurally different with a same mechanism of action serves as one good alternative (Lertcanawanichakul et al., 2007)

Due to the emergence of resistance to antimicrobial agents among Staphylococcus, accurate isolation of species and their antimicrobial susceptibility data is an essential factor in making appropriate therapeutic decisions.

\section{Materials and Methods}

This Descriptive cross sectional study was carried out in the Bacteriology Department of Microbiology of National Institute of Medical Sciences (NIMS) University, Jaipur, DistrictJaipur, Rajasthan, India for a period of six months (Jan. 2016 to June 2016). A total of 400 clinical specimens were found culture positive in the laboratory during the study period. The organisms isolated and identified provisionally as CoNS $(n=60)$ were identified further by using a standard protocol for identification (Koneman et al., 1997).

The present study was carried out on total 60 Coagulase Negative Staphylococcus (CoNS) were isolated from 400 different clinical samples like Urine, Blood, Pus, Sputum, High Vaginal Swab, Semen, Nasal Swab and ET Secretion etc. from all age's group and both sex attending OPD, IPD, ICU and Wards in hospital, during the study period. Isolation of various isolates was confirmed by several of test like Colony Characters, Morphology (Gram's stain) and Biochemical tests like Catalase and Coagulase Test (By Slide and Tube Method), Urease Test, Pyrrolidonyl Arylamidase (PYR) Test, Ornithine Decarboxylase Test, Sugar (Mannitol, Trehalose, Mannose) Fermentation Test, Cefoxitin Disk Diffusion Test, Novobiocin Susceptibility Test etc. were done for isolation of Coagulase Negative Staphylococcus (CoNS) (Fig. 2, 3 and 4).

\section{Antimicrobial susceptibility}

Antibiotic Susceptibility Testing was done by Modified Kirby Bauer's disc diffusion method as per CLSI guidelines 2014 using commercially available discs.

\section{Results and Discussion}

A total 60 strains of Coagulase Negative Staphylococcus (CoNS) were isolated from 400 various non-repetitive various clinical samples. Incidence of Coagulase Negative Staphylococcus (CoNS) isolates from clinical samples was $15 \%$.

Staphylococcus epidermidis was the most common isolate $(38.33 \%)$ while Staphylococcus saprophyticus (35\%) was the second most common isolated followed by Staphylococcus haemolyticus (15\%), Staphylococcus lugdanensis (5\%), Staphylococcus schleiferi and Staphylococcus xylosis have same account $(3.33 \%)$. Out of total 400 samples $226(56.50 \%)$ samples from Male while 174 (43.50 \%) from Female Patient. 
Out of total 400 samples, maximum from age group between 21-30 years i.e. $25 \%$ while minimum from $<10$ years of age i.e. $7.25 \%$.

We had maximum Urine samples (41.75\%), followed by Pus (24\%), Sputum (9\%), High vaginal swab (6\%), Blood (4.25\%), CSF (4\%) Pleural fluid (3.75\%), ET secretion (3\%), Ear swab (1.5\%), Semen (1\%), Nasal swab, Catheter tip (Each $0.75 \%$ ) and Ascetic fluid $(0.25 \%)$ (Fig. 5).

Maximum samples of over study were sterile (49.25\%). Gram Negative Bacilli (25\%) predominantly isolated in our study, followed by Coagulase Negative Staphylococcus (CoNS) (15\%) and GPC (other than CoNS) (9.75\%) (Fig. 6).

Out of Total 60 isolates of Coagulase Negative Staphylococcus, 32 (53.33\%) isolates from Male while 28 (46.67\%) from Female patient.

Staphylococcus epidermidis was the most common isolate $(38.33 \%)$ while Staphylococcus saprophyticus (35\%) was the second most common isolated followed by Staphylococcus haemolyticus (15\%), Staphylococcus lugdanensis (5\%), Both Staphylococcus schleiferi and Staphylococcus xylosis have same account (3.33\%) (Table1).

Among all Clinical Samples Urine yield maximum isolates of CoNS i.e. $26(43.33 \%)$ followed by Blood 10 (16.67\%), Pus 9 (15\%), Sputum 6 (10\%), High Vaginal Swab 5 (8.33\%) Semen 2(3.33\%) Same account of Nasal Swab and ET 1 (1.67\%) (Table No.-1)

\section{Antibiotic sensitivity testing results}

Out of 60 isolates of NFGNB were processed for Antibiotic susceptibility testing was done by Modified Kirby Bauer's disc diffusion method as per CLSI guidelines 2014 using commercially available discs. The antimicrobial sensitivity testing of isolated CoNS as a pathogen showed that $100 \%$ of Staphylococcus epidermidis were sensitive to Vancomycin and Novobiocin followed by Linezolid (78.26\%), Amikacin (65.21\%), Amoxicillin (60.86\%), Gentamycin, Cefotaxime and Cefoxitin (56.52\%), Ceftazidime (52.17\%), Clindamycin and Cefepime (47.82\%), Chloramphenicol (43.47\%), Cotrimoxazole (39.13\%), Erythromycin (34.78\%), Ciprofloxacin $(30.43 \%)$ and Penicillin-G $(21.73 \%)$ (Table 3; Fig. 7).

The second most isolated CoNS, Staphylococcus saprophyticus showed highest sensitivity $100 \%$ Vancomycin followed by Linezolid (85.71\%), Amikacin, Cefepime and Amoxicillin (80.95\%), Cefoxitin (76.19\%), Ciprofloxacin (66.66\%), Clindamycin and Ceftazidime (61.90\%), Cefotaxime and Chloramphenicol (57.14\%), Gentamycin and Erythromycin $(47.61 \%)$, Cotrimoxazole and Penicillin-G (28.57\%) (Table 3; Fig. 7).

Staphylococcus haemolyticus showed highest sensitivity $100 \%$ Vancomycin, Novobiocin and Linezolid followed by Gentamycin (66.66\%), Amoxicillin, Clindamycin, Amikacin, Chloramphenicol, Cefepime and Cefoxitin (55.55\%), Cefotaxime, Cotrimoxazole and Erythromycin (44.44\%), Penicillin-G and Ceftazidime (33.33\%) (Table 3; Fig. 7).

Staphylococcus lugdunensis were $100 \%$ sensitive to Vancomycin, Novobiocin Amoxicillin Amikacin Cefotaxime Gentamycin Linezolid Cefoxitin followed by Cefepime and Chloramphenicol Clindamycin $(66.66 \%)$, Erythromycin, Ceftazidime and Cotrimoxazole (33.33\%) (Table 3; Fig. 7). 
Table.1 Distribution of CoNS species in Various Clinical Samples

\begin{tabular}{|l|c|c|c|c|c|c|c|c|c|c|}
\hline CoNS Species & Urine & Pus & Blood & Sputum & HVS & Semen & $\begin{array}{c}\text { Nasal } \\
\text { Swab }\end{array}$ & ET Secretion & $\begin{array}{c}\text { Total } \\
\text { Percentage } \\
(\%)\end{array}$ \\
\hline $\begin{array}{l}\text { Staphylococcus } \\
\text { epidermidis }\end{array}$ & 5 & 5 & 4 & 4 & 3 & - & 1 & 1 & 23 & $38.33 \%$ \\
\hline $\begin{array}{l}\text { Staphylococcus } \\
\text { haemolyticus }\end{array}$ & 2 & 2 & 3 & - & 1 & 1 & - & - & 9 & $15 \%$ \\
\hline $\begin{array}{l}\text { Staphylococcus } \\
\text { lugdunensis }\end{array}$ & - & 1 & 2 & - & - & - & - & - & 3 & $5 \%$ \\
\hline $\begin{array}{l}\text { Staphylococcus } \\
\text { schleiferi }\end{array}$ & - & - & - & 2 & - & - & - & - & 2 & $3.33 \%$ \\
\hline $\begin{array}{l}\text { Staphylococcus } \\
\text { saprophyticus }\end{array}$ & 19 & - & - & & 1 & 1 & - & - & 21 & $35 \%$ \\
\hline $\begin{array}{l}\text { Staphylococcus } \\
\text { xylosis }\end{array}$ & - & 1 & 1 & - & - & - & - & - & 2 & $3.33 \%$ \\
\hline
\end{tabular}

Table.2 Distribution of Methicillin Sensitive and Methicillin Resistant CoNS species

\begin{tabular}{|l|}
\hline CoNS Species \\
\hline Staphylococcus epidermidis \\
\hline Staphylococcus haemolyticus \\
\hline Staphylococcus lugdanensis \\
\hline Staphylococcus schleiferi \\
\hline Staphylococcus saprophyticus \\
\hline Staphylococcus xylosis \\
\hline Total \\
\hline
\end{tabular}

\begin{tabular}{|c|c|c|}
\hline Number of Strains Tested & Number of MSCoNS & $\begin{array}{c}\text { Number of } \\
\text { MRCoNS }\end{array}$ \\
\hline 23 & 13 & 10 \\
\hline 9 & 5 & 4 \\
\hline 3 & 3 & - \\
\hline 21 & 2 & - \\
\hline 2 & 16 & 5 \\
\hline 60 & - & 2 \\
\hline
\end{tabular}

Table.3 Species wise Antibiotic susceptibility pattern of Coagulase Negative Staphylococcus (CoNS)

\begin{tabular}{|c|c|c|c|c|c|c|c|c|c|c|c|c|}
\hline \multirow[t]{2}{*}{$\begin{array}{c}\text { Name of the } \\
\text { antibiotic }\end{array}$} & \multicolumn{2}{|c|}{$\begin{array}{l}\text { S. epidermidis } \\
(n=23)\end{array}$} & \multicolumn{2}{|c|}{$\begin{array}{c}\text { S. saprophyticus } \\
(\mathrm{n}=21)\end{array}$} & \multicolumn{2}{|c|}{$\begin{array}{l}\text { S. haemolyticus } \\
(\mathrm{n}=9)\end{array}$} & \multicolumn{2}{|c|}{$\begin{array}{l}\text { S. lugdunensis } \\
\qquad(\mathrm{n}=3)\end{array}$} & \multicolumn{2}{|c|}{$\begin{array}{c}\text { S. schleiferi } \\
(\mathrm{n}=2)\end{array}$} & \multicolumn{2}{|c|}{$\begin{array}{l}\text { S. } x y \text { losis } \\
(\mathbf{n}=2)\end{array}$} \\
\hline & $\begin{array}{l}\text { No. of } \\
\text { Isolates }\end{array}$ & $\%$ & $\begin{array}{l}\text { No. of } \\
\text { Isolates }\end{array}$ & $\%$ & $\begin{array}{l}\text { No. of } \\
\text { Isolates }\end{array}$ & $\%$ & $\begin{array}{l}\text { No. of } \\
\text { Isolates }\end{array}$ & $\%$ & $\begin{array}{l}\text { No. of } \\
\text { Isolates }\end{array}$ & $\%$ & $\begin{array}{l}\text { No. of } \\
\text { Isolates }\end{array}$ & $\%$ \\
\hline Novobiocin & 23 & 100 & 0 & 0 & 9 & 100 & 3 & 100 & 02 & 100 & 0 & 0 \\
\hline Penicillin-G & 05 & 21.73 & 06 & 28.57 & 03 & 33.33 & 0 & 0 & 0 & 0 & 0 & 0 \\
\hline Amoxicillin & 14 & 60.86 & 17 & 80.95 & 05 & 55.55 & 03 & 100 & 02 & 100 & 0 & 0 \\
\hline Clindamycin & 11 & 47.82 & 13 & 61.90 & 05 & 55.55 & 02 & 66.66 & 02 & 100 & 0 & 0 \\
\hline Erythromycin & 08 & 34.78 & 10 & 47.61 & 04 & 44.44 & 01 & 33.33 & 02 & 100 & 0 & 0 \\
\hline Ciprofloxacin & 07 & 30.43 & 14 & 66.66 & 0 & 0 & 0 & 0 & 0 & 0 & 0 & 0 \\
\hline Amikacin & 15 & 65.21 & 17 & 80.95 & 05 & 55.55 & 03 & 100 & 02 & 100 & 01 & 50 \\
\hline $\begin{array}{l}\text { Chloramphenico } \\
\text { I }\end{array}$ & 10 & 43.47 & 12 & 57.14 & 05 & 55.55 & 02 & 66.66 & 02 & 100 & 01 & 50 \\
\hline Ceftazidime & 12 & 52.17 & 13 & 61.90 & 03 & 33.33 & 01 & 33.33 & 01 & 50 & 01 & 50 \\
\hline Cefepime & 11 & 47.82 & 17 & 80.95 & 05 & 55.55 & 02 & 66.66 & 01 & 50 & 02 & 100 \\
\hline Cefotaxime & 13 & 56.52 & 12 & 57.14 & 04 & 44.44 & 03 & 100 & 01 & 50 & 0 & 0 \\
\hline Cotrimoxazole & 09 & 39.13 & 06 & 28.57 & 04 & 44.44 & 01 & 33.3 & 01 & 50 & 01 & 50 \\
\hline Gentamycin & 13 & 56.52 & 10 & 47.61 & 06 & 66.66 & 03 & 100 & 02 & 100 & 01 & 50 \\
\hline Vancomycin & 23 & 100 & 21 & 100 & 9 & 100 & 03 & 100 & 02 & 100 & 2 & 100 \\
\hline Linezolid & 18 & 78.26 & 18 & 85.71 & 9 & 100 & 03 & 100 & 02 & 100 & 02 & 100 \\
\hline Cefoxitin & 13 & 56.52 & 16 & 76.19 & 05 & 55.55 & 03 & 100 & 02 & 100 & 0 & 0 \\
\hline
\end{tabular}


Fig.1 Growth of CoNS on Blood Agar Media

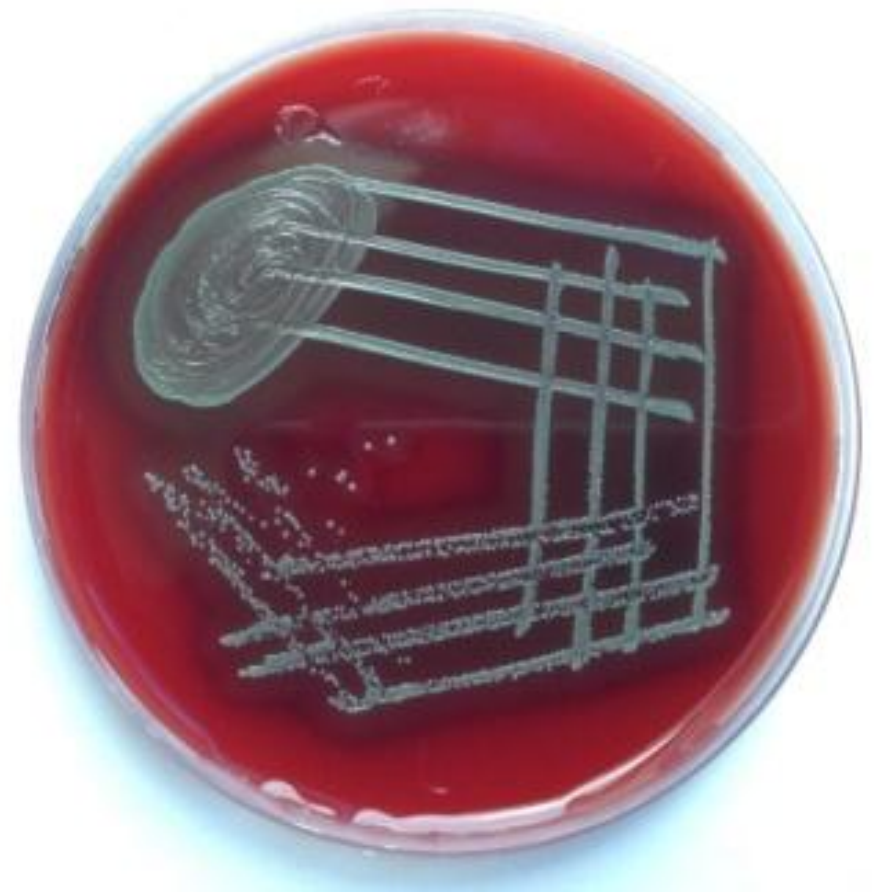

Fig.2 PYR Test (Test Strain Positive)




Fig.3 Ornithine Decarboxylase Test (Test Strain Positive)

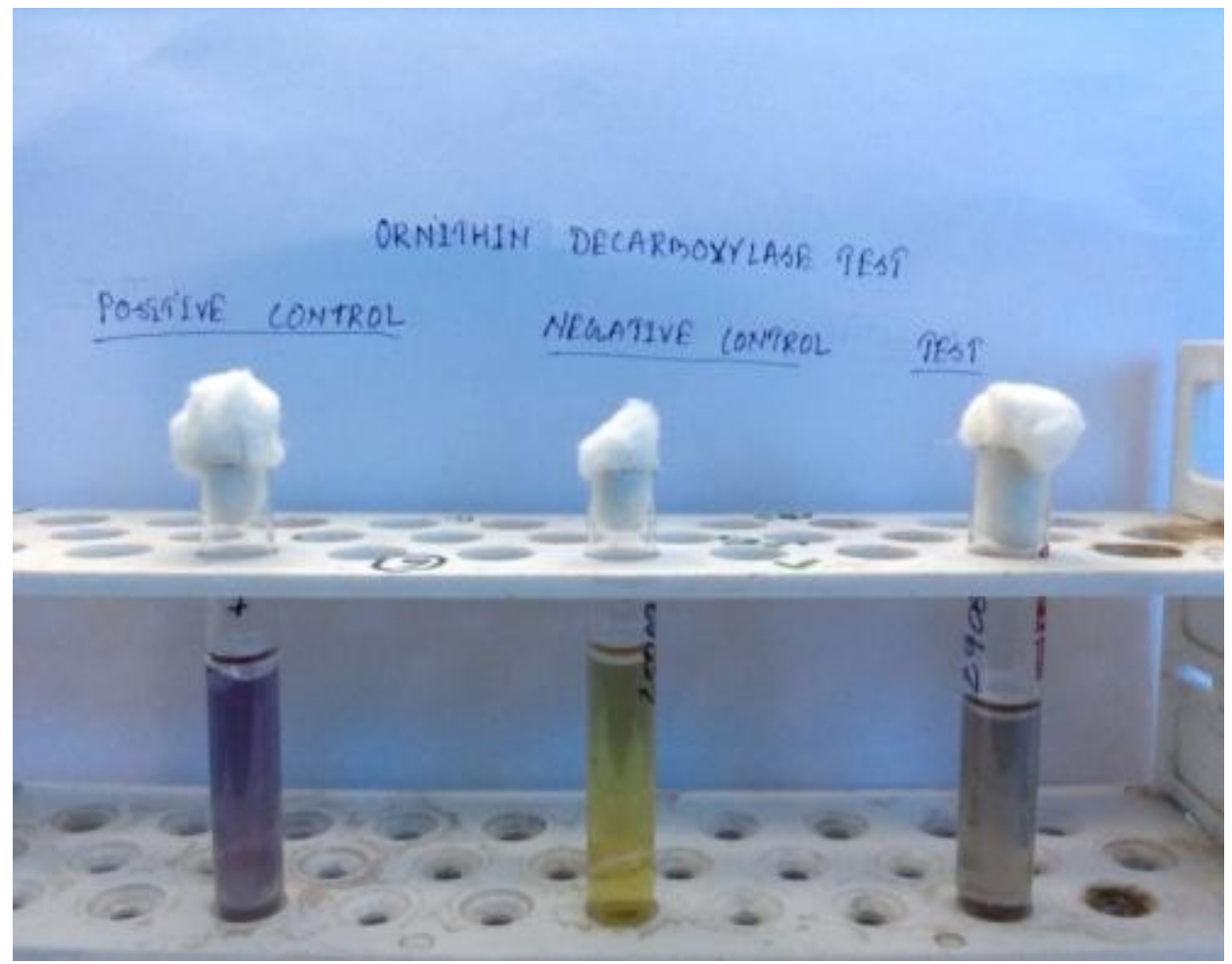

Fig.4 Cefoxitin Disk Diffusion Test

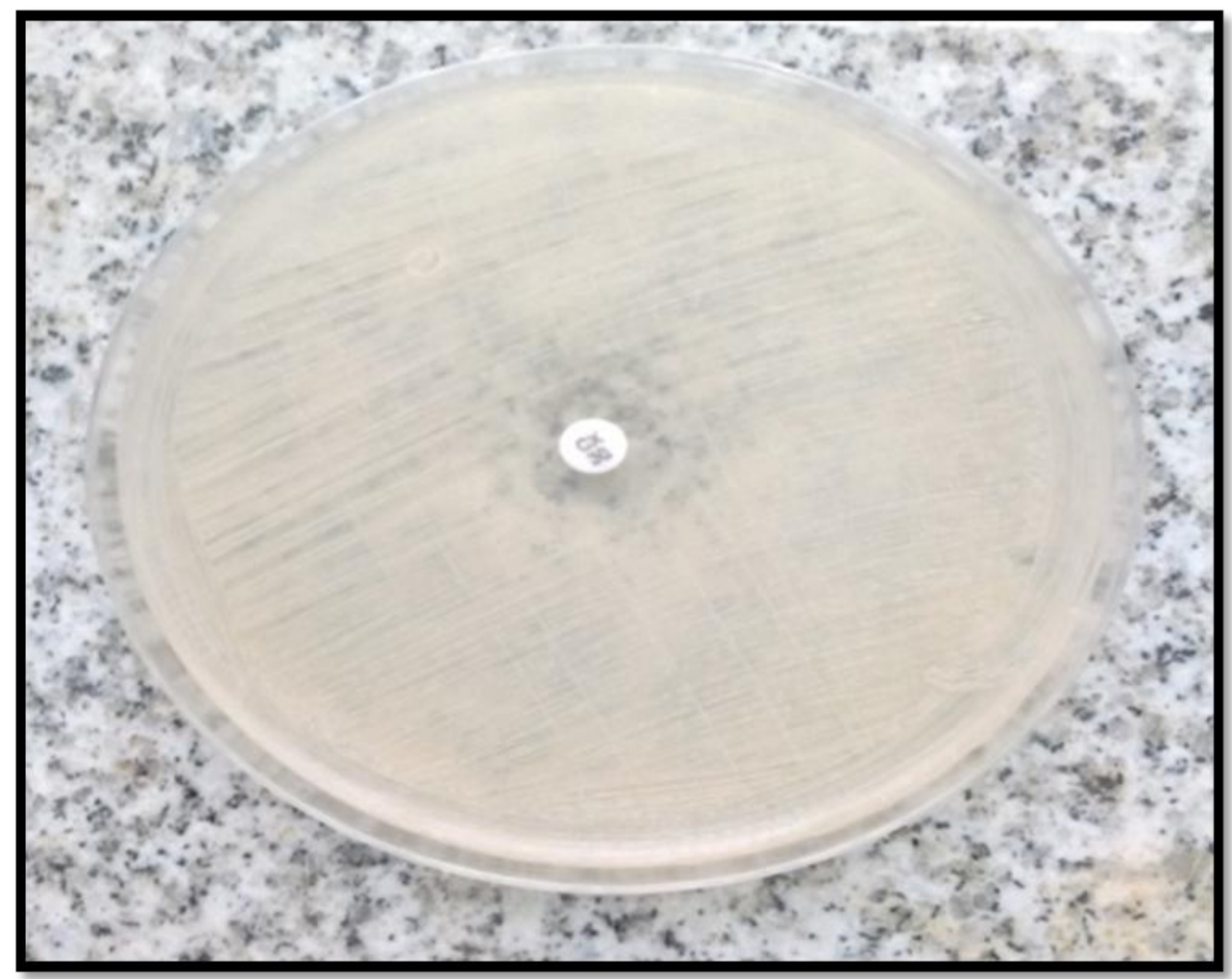


Fig. No. 5: Distribution of Various Types of Clinical Samples $(n=400)$

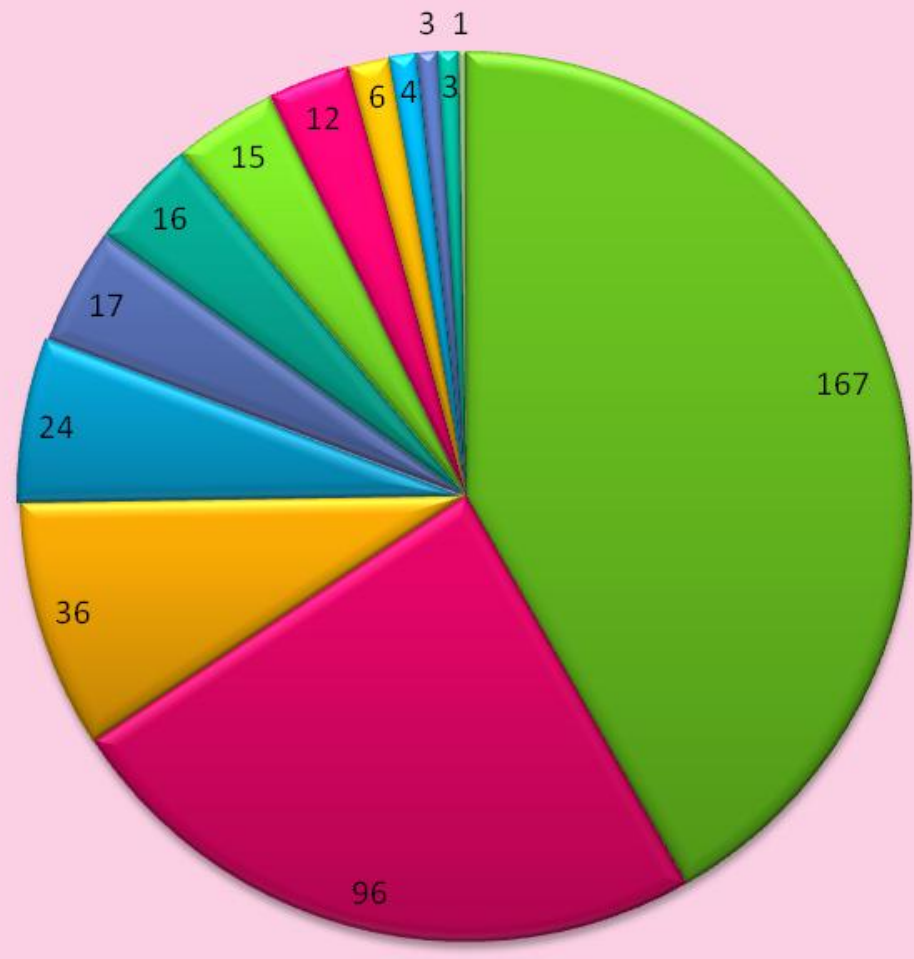

$\checkmark$ Urine

口 Pus

$\square$ Sputum

$\square$ High Vaginal swab

$\square$ Blood

$\square \mathrm{CSF}$

$\square$ Pleural Fluid

Endotracheal secretion

$\square$ Ear Swab

$\square$ Semen

Nasal Swab

$\square$ Catheter Tip

$\triangle$ Ascetic Fluid

Fig. No. 6: Isolation Rate of Various Organisms in Clinical Samples

$(n=400)$

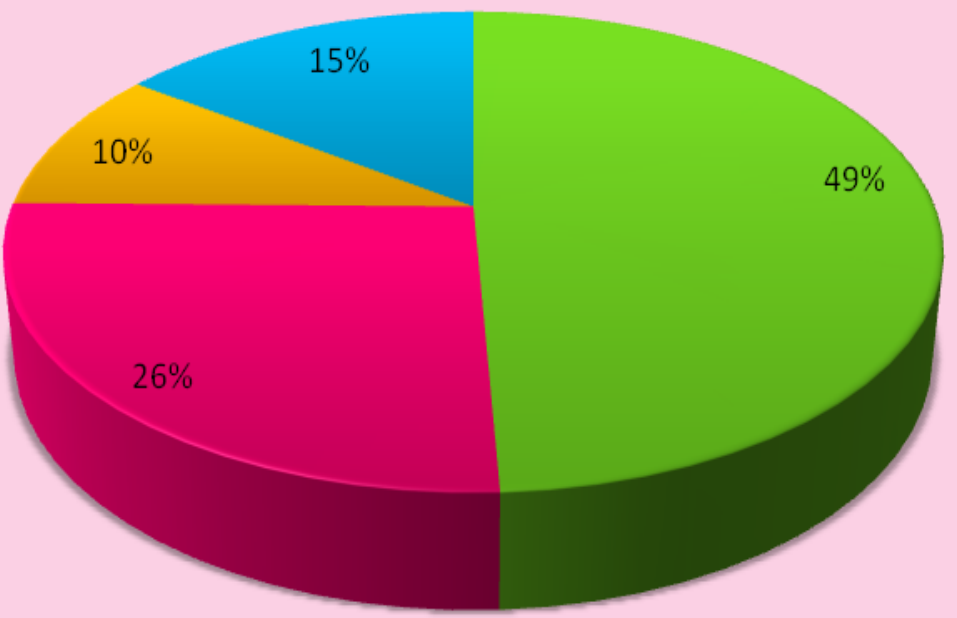

$\square$ Sterile

vGNB

$\triangle \mathrm{GPC}$ (other than CoNS)

$\square$ CoNS 




Staphylococcus schleiferi were $100 \%$ sensitive to Vancomycin, Novobiocin, Amoxicillin, Amikacin, Gentamycin, Linezolid, Cefoxitin, Clindamycin, Erythromycin and Chloramphenicol followed by Cefepime, Ceftazidime, Cefotaxime and Cotrimoxazole (50\%) (Table 3; Fig. 7).

Staphylococcus xylosis were $100 \%$ sensitive to Vancomycin, Linezolid, Cefepime followed by Amikacin, Chloramphenicol, Ceftazidime, Cotrimoxazole and Gentamycin (50\%) (Table 3; Fig. 7).

In our study the CoNS infection was more common in males $(53.33 \%)$ than in females $(46.67 \%)$ in the present study, which is similar to other by Usha et al., (2016) also showed that male had more infection with CoNS than females.

In the Present Study out of the total of 400 relevant clinical samples collected, $60(15 \%)$ samples were identified as Coagulase
Negative Staphylococcus (CoNS), which is similar to other by Roopa et al., (2015) where Out of the total of 723 relevant clinical samples, 112 (15.4\%) samples revealed growth of Coagulase Negative Staphylococcus (CoNS) on culture.

Out of the 60 isolates, most of isolates (43.33\%) were from Urine, followed by Blood (16.67\%), Pus (15\%), 10\% from Sputum, $8.33 \%$ from HVS, $3.3 \%$ from Semen, $1.67 \%$ from both Nasal Swab and ET secretion. In other studies like Roopa et al., (2015) isolated CoNS (77\%) more in Wound swabs/samples. Study done by Usha et al., (2016) revealed CoNS (52.94\%) more in blood samples. This difference may be due to difference in availability of samples.

The highest number of CoNS isolates were Staphylococcus epidermidis (38.33\%) followed by Staphylococcus saprophyticus $(35 \%)$. The other species isolated were Staphylococcus haemolyticus

$(15 \%)$, 
Staphylococcus lugdunensis (5\%), Staphylococcus schleiferi and Staphylococcus xylosis both are (3.33\%).

In Our Study, the most commonly isolated species was Staphylococcus epidermidis similar to other studies as shown by Sheikh $e t$ al., (2012) and Asangi et al., (2011) also showed that Staphylococcus epidermidis is the most commonly isolated species from clinical specimens, seen in $19.40 \%$ and $44.8 \%$ respectively.

The Second most common species in our study was Staphylococcus saprophyticus seen in $35 \%$, similar results were seen in other studies also like in study done by Goyal et al., (2006) but in other studies, it was Staphylococcus hemolyticus in Usha et al., (2016) and Staphylococcus hominis in the study by Manikandan et al., (2005).

In Urine sample of Our Study, Staphylococcus saprophyticus was the predominant species, followed by Staphylococcus epidermidis and Staphylococcus haemolyticus. Similar result observed by Roopa et al., (2015).

Staphylococcus saprophyticus was also the frequently isolated species from HVS and Semen. In pus sample of our study, Staphylococcus epidermidis was the most common species isolated. These findings are similar to the findings by various studies done on CoNS by Roopa et al., (2015).

Discussion of Antibiotic Sensitivity and Resistance of Coagulase Negative Staphylococcus (CoNS)

In Present Study, the Vancomycin was sensitive in all the isolates. Similar result found by Roopa et al., (2015) where Vancomycin was $100 \%$ sensitive.
Penicillin was most Resistant Antibiotic in CoNS in our study; similar to Habeeb Khadri et al., (2010). Out of 60 Coagulase Negative Staphylococcus (CoNS), 21 (35\%) were Methicillin Resistant in Coagulase Negative Staphylococcus (MRCoNS). Similar result (39.4\%) found by Habeeb Khadri et al., (2010).

We have observed that the resistant rate to different antibiotics among MRCoNS strains was higher than those sensitive to Methicillin and this phenomenon was reported by Tahnkiwale et al., (2002).

In Our Study we found that among 60 CoNS isolates, 16 isolates (26.66\%) showed constitutive resistance pattern and 11 isolates $(18.33 \%)$ were D-test positive and showed inducible Resistance. These finding are similar to Bansal et al., (2012).

\section{Acknowledgement}

The authors are thankful to the Department of Microbiology of National Institute of Medical Sciences (NIMS) Medical College, Jaipur (Raj.) for providing necessary laboratory facilities to carry out this work.

\section{References}

Anand KB, Agrawal P, Kumar S, Kapila K. 2009. Comparison of cefoxitin disc diffusion test, oxacillin screen agar, and PCR for mecA gene for detection of MRSA. Indian J Med Microbiol. 27(1): 27- 9 .

Asangi SY, Mariraj J, Sathyanarayan MS, Nagabhushan R. 2011. Speciation of clinically significant Coagulase Negative Staphylococci and their antibiotic resistant pattern in a tertiary care hospital. Int J Biol Med Res. (2): 735-9.

Bansal N, Chaudhary U, Gupta V. 2012. 
Prevalence of inducible Clindamycin resistance in clinical isolates of Coagulase Negative Staphylococci at a tertiary care hospital. Ann Trop Med Public Health. (5): 427- 430.

Bearson BL, Labarca JA, Brankovic LE, Cohen M, Bruckner DA, Pegues DA. 2004. Use of quantitative antibiogram analysis to determine the clonality of Coagulase Negative Staphylococcus species from blood culture. Clin Microbiol and Infect 10: 148-155.

Chaudhury A, Kumar A G. 2007. In vitro activity of antimicrobial agents against oxacillin resistant Staphylococci with special reference to Staphylococcus haemolyticus. Indian J Med Microbiol. 25: 50-52.

Clinical and laboratory standards institute (CLSI). 2014. Performance standards for antimicrobial Susceptibility testing, $27^{\text {th }}$ Ed Wayne, USA.

Cunha, M.L.R.S., E. Peresi, R.A.O. Calsolari, J.P. Araújo Jr. 2006. Braz J Microbiol. 37: 64-69

Dar JA, Thoker MA, Khan JA, Ali A, Khan MA, Rizwan M, Bhat KH, Dar MJ, Ahmed N, Ahmad S. 2006. Molecular epidemiology of clinical and carrier strains of Methicillin Resistant Staphylococcus aureus (MRSA) in the hospital settings of north India. Ann Clin Microbiol Antimicrob. 14: 5:22.

David Greenwood, Mike Barer, Richard Slack, Will Irving. 2012. Medical Microbiology, eighteen edition. Staphylococcus. P- 181.

De Lencastre, H., A M Sá Figueiredo, C Urban, J Rahal, A Tomasz. 1991. Multiple mechanisms of Methicillin Resistance and improved methods for detection in clinical isolates of Staphylococcus aureus. Antimicrob. Agents Chemother. 35(4): 632-639.

Deurenberg RH, Vink C, Kalenic S, Friedrich AW, Bruggeman CA, Stobberingh EE.
2007. The molecular evolution of Methicillin Resistant Staphylococcus aureus. Clin Microbiol Infect. 13(3): 222-235.

Goyal R, Singh NP, Kumar A, Kaur I, Singh M, Sunita N, Mathur M. 2006. Simple and economical method for resisitotyping of clinically significant Coagulase Negative Staphylococcus. Indian J med Microbiol. 24(3): 201204.

Habeeb Khadri, Mohammad Alzohairy. 2010. Prevalence and antibiotic susceptibility pattern of Methicillin Resistant Coagulase Negative Staphylococci in a tertiary care hospital in India. International Journal of Medicine and Medical Sciences. 2(4): 116-120.

Koneman EW, Winn WC Jr. Allen SD, Janda WM, Procop GW, Schreckenberger PC, Woods GL. 1997. Koneman's colour atlas and text book of diagnostic Microbiology. $5^{\text {th }}$ edn. Philadelphia: Lippincot Williams and WIkins Company. 547- 549.

Lertcanawanichakul M, Chawawisit K, Choopan A, Nakbud K, Dawveerakul K. 2007. Incidence of constitutive and inducible Clindamycin resistance in clinical isolates of Methicillin Resistant Staphylococcus aureus. Walailak J Sci Technol. 4: 155- 163.

Manikandan P, Bhaskar M, Revathy R, John RK, Narendran K, Narendran V. 2005. Speciation of Coagulase Negative Staphylococcus causing Bacterial Keratitis. Indian J Ophthalmol. 53:5960.

Parameswaran R, Sherchan JB, Muralidhar VD, Mukhopadhyay C, Vidyasagar S. 2011. Intravascular catheter-related infections in an Indian tertiary care hospital. J Infect Dev Ctries. 5: 452458.

Roopa, C., and Sunil kumar Biradar. 2015. Incidence and Speciation of Coagulase 
Negative Staphylococcus Isolates from Clinically Relevant Specimens with their Antibiotic Susceptibility Patterns. Int.J.Curr.Microbiol.App.Sci. 4(9): 975980.

Sheikh AF, Mehdinejad M. 2012. Identification and determination of Coagulase Negative Staphylococci species and antimicrobial susceptibility pattern of isolates from clinical specimens. Afr J Microbiol Res. 6:166974.

Tahnkiwale S, Roy S, Jalgaonkar S. 2002. Methicillin resistant among isolates of Staphylococcus aureus: Antibiotic sensitivity pattern and phage typing.
Indian J. Med. Sci. 56: 330-334.

Usha M. G., Shwetha D. C., Vishwanath G. 2016. Speciation of Coagulase Negative Staphylococcal isolates from clinically significant specimens and their antibiogram. ijpmonline. org. 14.139.244.

Valle, J., S. Vadillo, S. Piriz, E. GomezLucia. 1991. Appl Environ Microbiol 57: 889.

Wesley E. Kloosi, Tammy L. Bannerman. 1994. Update on clinical significance of Coagulase-negative Staphylococci. Clinical microbiology reviews. 117140.

\section{How to cite this article:}

Shiv Kumar, Jitendra, Anup Das, Pratibha Mane, Jyoti Sangwan and Saroj Kumari. 2018. Isolation, Identification and Antibiogram of Coagulase Negative Staphylococcus (CoNS) Isolated from Various Clinical Samples at a Tertiary Care Teaching Hospital, Jaipur, India. Int.J.Curr.Microbiol.App.Sci. 7(01): 3048-3059. doi: https://doi.org/10.20546/ijcmas.2018.701.362 